Jacek Pasła:wski

\title{
ON THE RELIABILITY OF THEMA'TIC MAPS
}

Prevalent opinion that the last blank spots were wiped out of maps of the world in the first half of the 19 th century serves as a good illustration of the efforts Europeans have been making for long centuries to learn the true image of our planet, the Earth. The map has thus growin to be a symbol of the process of cognition whereas the absence of blank spots is supposed to speak for the extent of our knowledge. However, as this has soon turned out, it is not sufficient to reach the head water of a stream or river, or to mark out the course-line of a mountain range, in order to fill in a blank spot on the map, as there would be hardly anyone to pretend that he has thoroughly learnt a piece of land through such facts.

More than twenty years ago W. Pillewizer ${ }^{1}$ complained that in a great many atlases reference maps are made so that they really can produce wrong image of the land represented by them. By quoting a number of examples he showed that the degree of cartographic cognizance of the Earth was so diverse that it was impossible to prepare well-reliable maps even in atlas scales suggested by him as ranging from $1: 1.5 \mathrm{M}$ to $1: 10 \mathrm{M}$. Although several years have gone since then, the problem still remains unsolved, as this can be seen from the newly-edited Africa and South America sheets of Map of the World. 1:2.5 M.

In W. Pillewizer's opinion, the reader of the map can be misinformed through the very fact that in atlas maps little reference is made to the degree of accuracy offered by basic material itself. And when reading a map, one may have an impression as if the basic material were equally reliable and accurate, in all its details, throughout the whole of the

1 W. Pillewizer, "Die Geländedarstellung in Atlaskarten und topographische Erschliessungszustand der Erde", Kartographische Nachrichten B. 11, No. 2, 1961, op. $29-33$. 
map. Such an impression will in many cases be wrong, if not specifically intended by the cartographer. Reliability diagrams of the basic material can only be found in the topographic maps, or rather seldom in the survey of reconnaissance maps of some special application.

In his article, W. Pillewizer concentrates himself on some specific art of thinking, characteristic of cartographers who usually think that no blank spots can be tolerated on the map and that a uniform mapping procedure is required throughout the whole of a map. Authors of the ancient maps would insert diverse specifications or decorative drawings to camouflage their ignorance. Aithough one can hardly talk of any blank spots today, in the sense of the completely unknown lands, we are nevertheless very far from knowing our planet to an extent that would leave no doubts in making thematic maps.

Interest taken in the reference maps has diminished in favour of the thematic maps over the recent decade. Maps highly diversified in their contents are made not only by geographers, but by other specialists as well. And it is a very rare case that the author of a map will acknowledge the fact that material in his possession lacks reliability, or is incomplete. Such a tendency is rather common among map makers, and it has to be admitted that - although not always aware - they tend to behave like those ancient cosmographers of the 16 th century who, in places devoid of reliable data, used to draw fancy creatures. However, the authors of today's thematic maps make use of some more sophisticated methods and it is sometimes very difficult to say whether we have to do with a map of really little value or not, and to what extent details contained therein are reliable. I am even thinking that many of the approved cartographic conventions have certain properties which help map makers to conceal shortcomings that the pro-duct of their work may contain in itself.

The technique of isolines seems to offer the greatest possibilities in this respect. Climatological maps in which isolines are drawn against data supplied from the strictly chosen control points can serve as an excellent example for this.

When looking at such maps, whether this will be a national atlas or a regional atlas, one can draw a conclusion that each map is equally dependable and that isolines presented in them are equally well justified throughout the entire represented area. But it may also happen so that quite irregular control points, which fail to reflect chance variation of the climate and its elments, have been chosen as a basis for marking out the lines. Looking at the map (Fig. 1A), the reader can identify both areas, the eastern and western one, as the areas of higher 

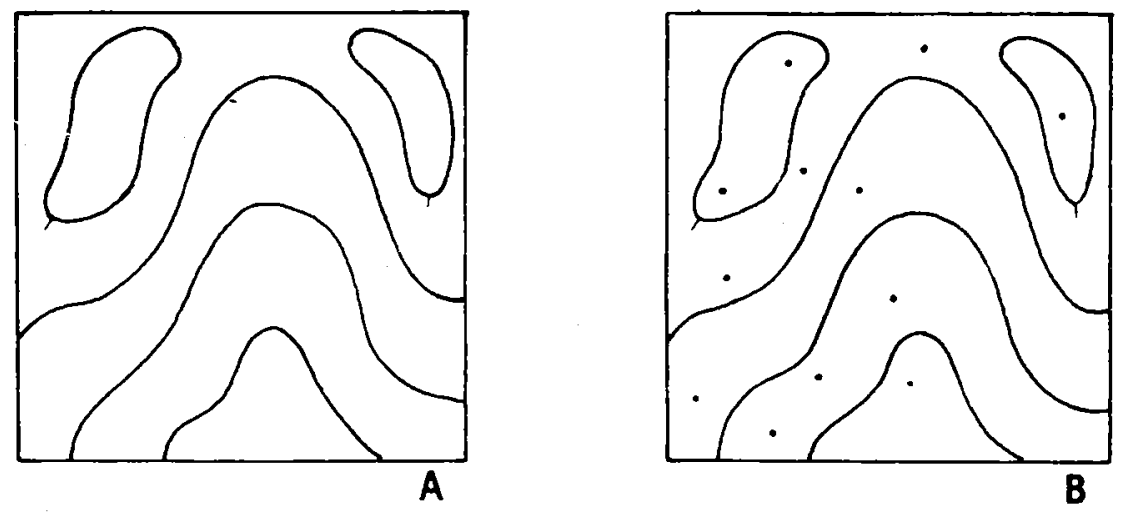

Fig. 1
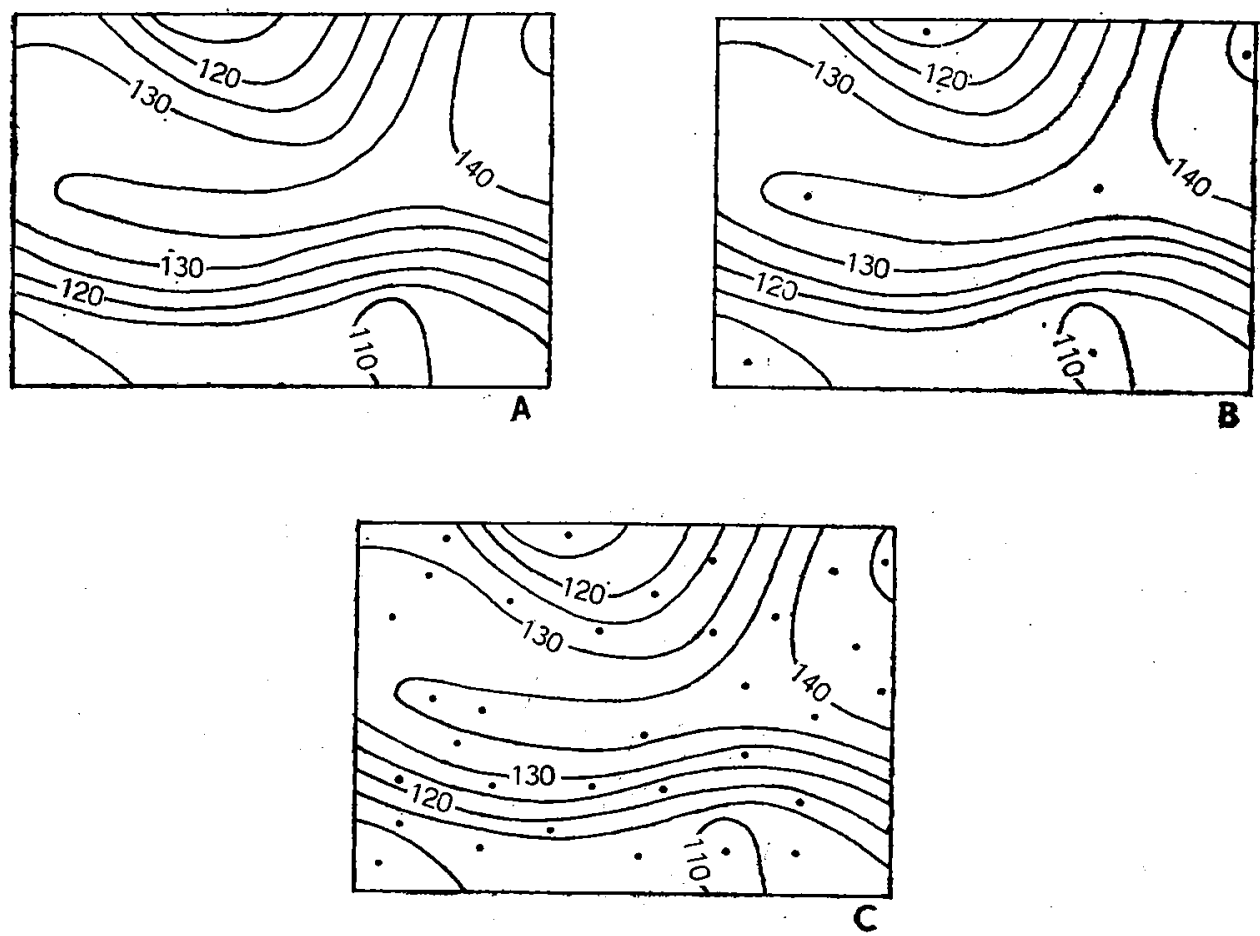

Fig. 2 
temperatures or higher pressure, although - after a more detailed study - he may notice that the western area was isolined against data taken from several control points, and the eastern from one point only (Fig. 1B). When analysing the cloud-cover map, you do not exactly $\mathrm{knc}$ w whether the central part with the relatively high amount of cloud was confirmed by observations from a few stations only (Fig. 2B), or from several scores of such stations (Fig. 2C).

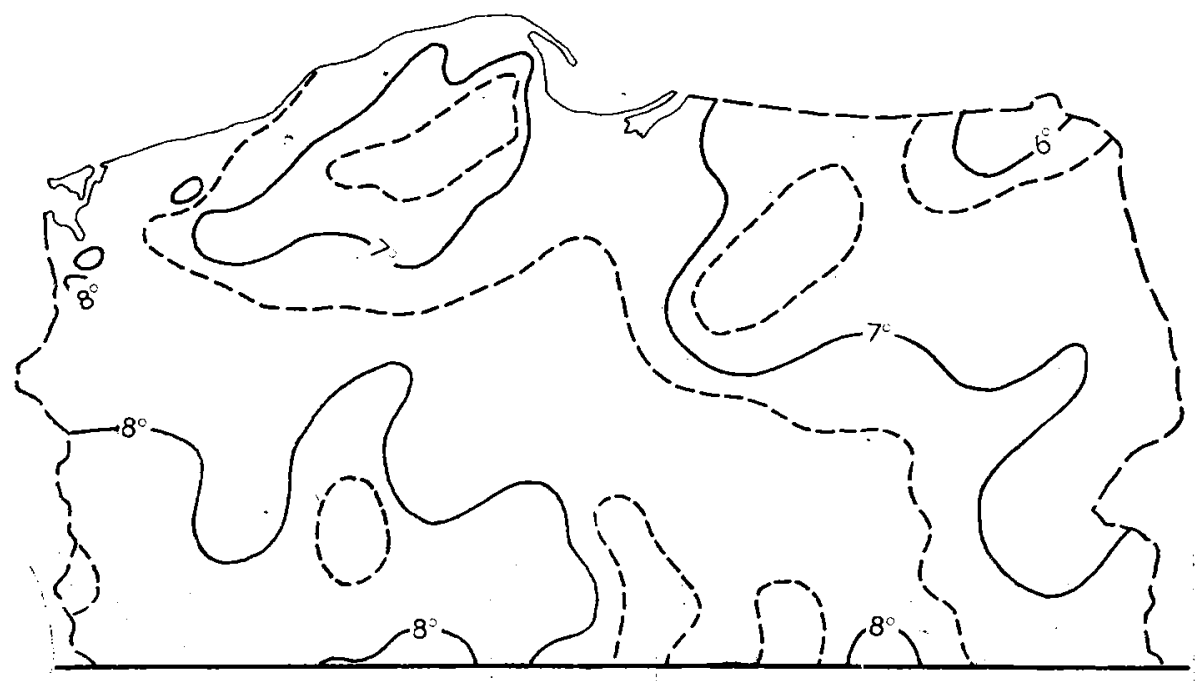

Fig. 3. Temperature of air (means for 1881-1930); scale $1: 7000000$

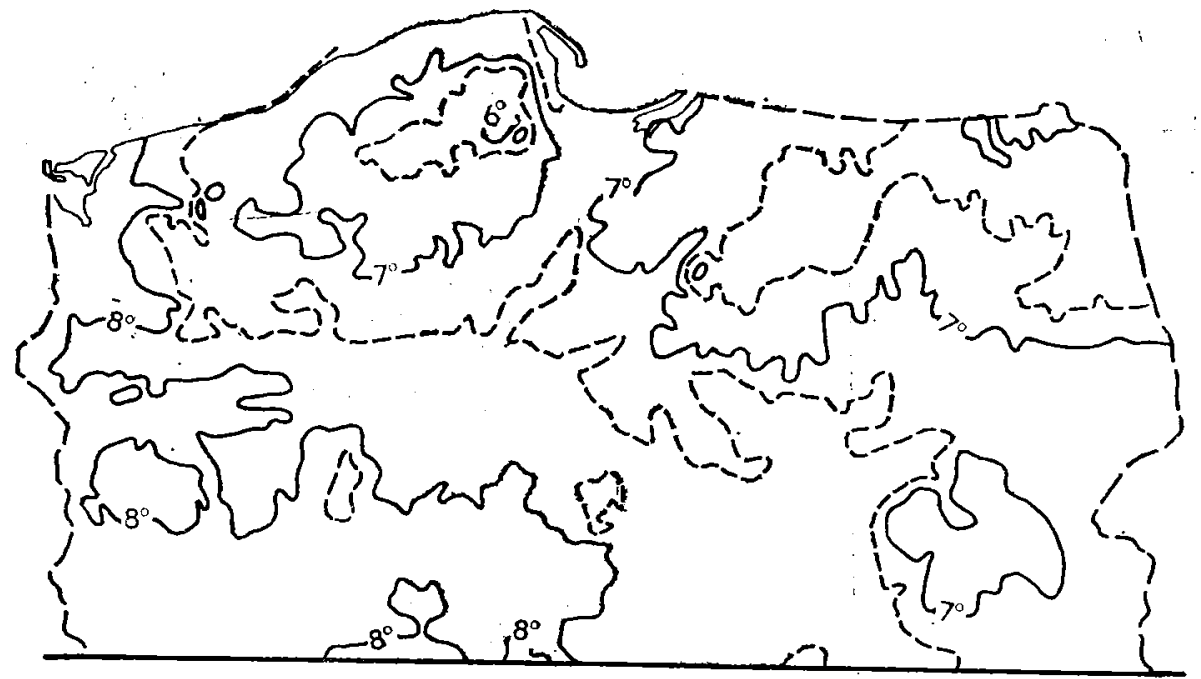

Fig. 4. Temperature of air (means for 1881-1930); scale 1:7000 000 
As spatial distribution of certain climatic elements seems to be definitely the function of land relief, map makers are often rather precise in drawing the pattern of isotherms. When glancing at such a map, the map reader can only guess to what extent the presented image is the product of interpretation furnished by the author himself. To confirm this, ycu have two maps in Fig. 3 and Fig. 4 both based on identical source material, but made by two different authors. ${ }^{2}$

When comparing two different isoline maps, a map reader may be struck by an apparently varying degree noticeable in the concentration of details. Whereas on one map the pattern of isolines seems to be rather intricate (Fig. 4), it looks almost schematic on the other (Fig. 5). The fact that the first map was drawn atgainst data cumulated from approximately 150 control points, and the other from only 90 points, can by no means be interpreted as an excuse for such a big difference between the two maps. ${ }^{3}$ It must therefore be beyond any doubt that we have to do with nothing else but a product of the author's personal interpretation, which the map reader is not in a position to assess himself.

From examples quoted it will be obvious that the secret of arriving at a proper interpretation of the isoline image lies in the control points marked on the map. Relevant information would be extremely useful to assess to what extent the pattern of isolines is likely to reflect the views of the author himself. While being in favour of the control points provided on the map so as not to make it graphically overloaded, in the form of dots, I am definitely against placing any extra figures on it such as, for example, statistical data. Since each map is designed to represent an image of the spatial distribution of geographical events, expressed by graphical means, we must avoid to make it a substitute

${ }^{2}$ Maps, Figs. 2A, 4, 5, attached herewith have been made by using the Narodowy Atlas Polski (National Atlas of Poland) as a basis. (Plates 26, 20 and 21) Maps as shown in Fig. 3 come from a textbook by W. Wiszniewski, G. Gumiński, L. Bartnicki, entitled „Przyczynki do klimatologii Polski” (Contributions to Poland's Climatology), Wiadomości Stużby Hydrologicznej i Meteorologicznej, Vol. I, No. 5, pp. 345-371.

The map in Fig. 6 comes from the paper by F. Uhorczak, "Wiojewództwo lubelskie na tle ogólnej charakterystyki fizjograficznej i gospodarczej województw Polski" (The Lublin Province against a BAckground of an Overall Physiographic and Econamic Situation in the Provinces of Poland), Przewodnik XII Ogólnopolskiego Zjazdu Polskiego Towarzystwa Geograficznego, Lublin 1974, pp. 139-212. Maps 7A, 7B and 7C represent fragments taken from the Atlas Województwa Katowickiego (Katowice Province Atlas), Warsaw 1971, p. 33.

3 The number of control points quoted applies to the map of the whole Poland. Figure embraces North Poland anly. 
of statistical data tables. Functions of the map and statistical tables vary a lot and connot be intermingled. A postulate to make control points in the afore-mentioned maps easily identifiable is by no means new, but it is extremely seldom brought into effect. ${ }^{4}$ It seems as if the cartographers wanted in such a way to conceal secrets of their expertise, but this - if it were so - might only go to the map user's detriment.

This situation is a little different for a map reader, when an isoline map has been made against the background of data relating to the statistical space units (as e.g. the population density maps). The problem of isolines being used to present such data remains controversial; and not only among cartographers, as this will — among other things - be obvious from the terminology suggested by those who oppose it. They are using such terms as ,pseudo-isolines” or „false isolines”. To be able to abandon isolines in such situations completely seems little likely, however, as they offer also some advantages that speak in favour of this method. ${ }^{5}$ But this must not be an opportunity to mislead map users or to misinform them.

First of all, maps of the latter type will differ from those described above. While the point of an isoline presentation is to reproduce the pattern of the continuous statistical surface, and to render theoretically justifiable readability of any freely chosen point on the map in terms of value, so in the case of isopleths such an operation will be comipletely useless. Statistical surface in the latter case may be approached exclusively as a reference model of spatial distribution, formed against a background of data relating to space units having an unknown internal variability. Unless a line of division is drawn between the two types of isolines, an erroneous interpretation of the map may often result even when this is done by the well-educated geographers.

We have to admit at this point that little has been done so far on the side of cartographers to draw readers' attention to the difference existing between the two types of maps. And this can actually be done in two ways. First of all, like the control points ought to be necessarily designated in the earlier discussed maps, so in the latter case the cartographer should be obliged to mark out boundaries of the space units which formed the basis for the mapping process. In such a way attention could be focused on a very essential feature of the maps, namely that the above-mentioned units may vary heavily both in area

4 One of the latest publications in which control points in the climatological maps have been shown with full consistency is the Atlas of the Slovak Socialist Republic, Bratislava 1981.

${ }^{5}$ In American literature isolines of that type are referred to as isopleths. 
and in shape. Much more interesting, however, remains the other way of indicating the special character these maps may have. To quote an example, Professor F. Uhorczak $(1902-1981)$ has been launching the rule of the so-called broken isolines since 1952. To draw them, you will have to connect by straight lines relevant points of the interpolation axes. Such a map will differ in its graphical expression from the "traditional" isolinear maps. Even an unskilled map reader, after having compared Fig. 6 with Figs. 1-5, will find the sense of presentation being quite different in the two cases.

Cartographers have been eager, so far, to blur this difference by saying little convincingly that broken isolines fail to be natural in their pictorial presentation. In my opinion, most of the map readers can hardly tell one type of the isolinear map from the other. For instance, P. Gould's mental maps 'which use the technique of isolines are procured against data relating to the space units (such as states or provinces). A false construction is often put on them, I think, because of the "traditional" way in which the isolines are drawn.

Surprisingly enough, cartographers appear to be rather fond of the idea according to which aesthetics is put before merits of a project. Cartographers, often influenced by draughtsmen, tend to simplify drawing of the map whereby the latter loses much of the information intended for the map users, and choropleth maps are likely to suffer most from such simplifications. It often happens that boundaries of the adjoining statistical units, falling under the same class of a choropleth map, are left out and form in such a way as if new units.

Much has been written on the effects space units exert on the structure of data collected, and hence on the cartographic image as well. It is, an the other hand, known that only units identical in size and shape can guarantee truly comparable data. A sentence that "density of population in Poland ranged from 746 to 41 inhabitants per square kilometre in 1981" cannot be true unless the words "... in provincial units, i.e. voivodships", are added. ${ }^{6}$ Cartographers seem to forget about these requirements and map readers suddenly stand before an apparently different space division, although one and the same area is presented on each of the successive chioropleth maps being studied. Choropleth maps with not all space units relevantly marked on them will be like isolinear maps (see Figs. 7A, 7B, 7C) lacking control points.

No less doubtful will be the use of various diagrams on such maps, and above all the way in which they are being explained. When the

6 Poland has been divided into forty nine provinces ranging from 1.5 thou. sq.km to 12.3 thou. sq.km in area. The average of area is 6.4 thou. sq.km. 
range of statistical data is really extensive, authors of textbooks suggest that solids, such as spheres or cubes, should be introduced, proportional in volume to the amount of statistical data. Diagrams of the latter type need much less space, less even than the corresponding two-dimensional figures. The only problem facing map readers is that they are not in a position to evaluate rightly their size, nor relations existing between the diagrams. Despite so many maps of this type in circulation, no explicit recommendations have been furnished so far on how legends must be worked out to make such maps well readable. Experiments as carried out in the past, even with regard to the easier-acceptable circular diagrams, are neither univocal in their outcome, nor - as this can be noted from maps in use - more popular among the authors of cartographic publications.

The construction of legends in most thematic maps raises serious doubts as to whether such legends help the reader to make the use of maps easier. For instance, explanations on choropleth maps and isoline maps most frequently take the form of boxes which ideally blur such an essential information as the variable range of classes is. It will be both the graphic form of such a legend as well as specification contained therein that can often be described as "masking" appropriate quantitative relations existing between categories specified. The scale as seen in Fig. 8A is often found in the atlases, but - to my mind the number of map readers likely to imagine with its help the actual relations in the range of thus explained classes (Fig. $8 \mathrm{~B}$ ) must be rather sma.ll. While leaving behind lots of doubts about legends of choropleths and isoline maps, I would like to refer you to my article ${ }^{7}$ on differences and similarities between the two.

Examples quoted indicate that the same established patterns are invariably adopted in making the thematic maps. These paterns are not always worthy of being followed, and several examples may be quoted when the map itself or explanation given on it not only fail to fulfil their functions but may even lead the map reader astray as well.

There is much evidence for the fact that thematic maps have not yet reached the standard of reliability the topographic maps have. This, no doubt, results from the fact that the thematic cartography, as a discipline, is much younger and has yet a long way to go. That is one of the reasons for reservations noted among research workers of various

7 J. Paskawski: „Natural Legend Design for Thematic Maps”, The Cartographic Journal 20, No. 1, 1983, pp. 36-37, No. 2, pp. 148. 
lines, for under such circumstances maps in question can be regarded neither as a dependable source of information, nor as an efficient instrument for research work. There is, therefore, an urgent need for studies to be oriented so as the render thematic maps a much more reliable instrument of work for each scientist.

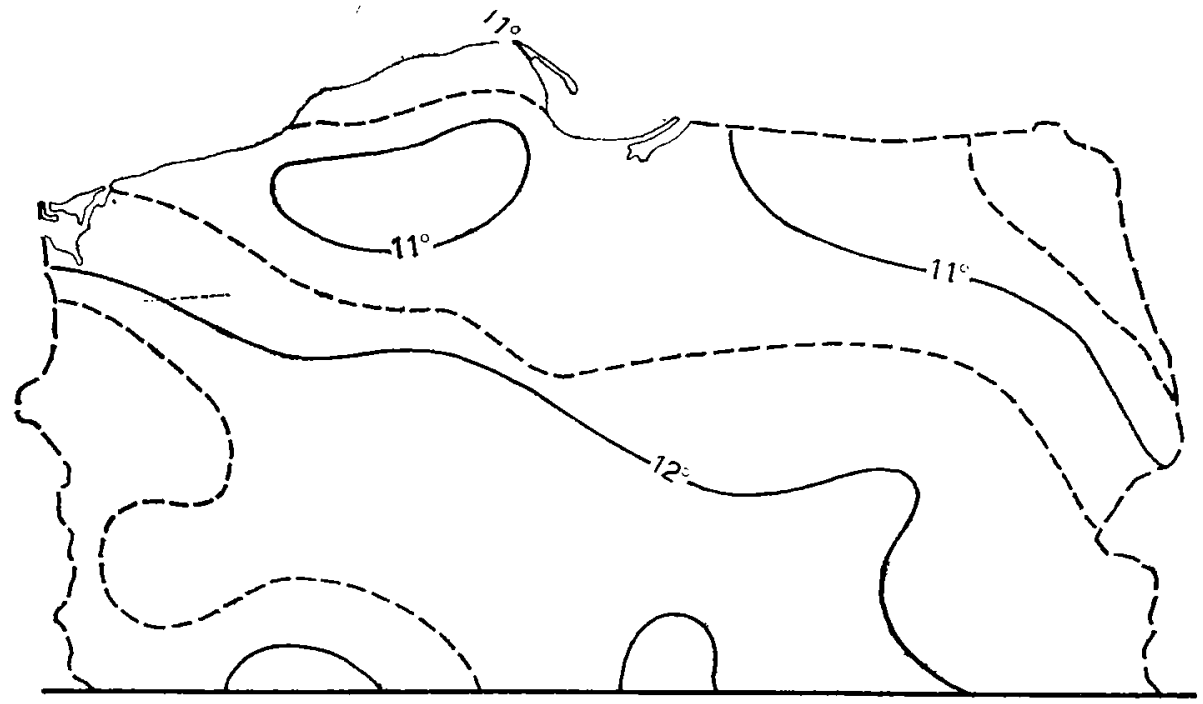

Fig. 5. Maximum air temperature (mean for 1951-1960); scale 1:7000000

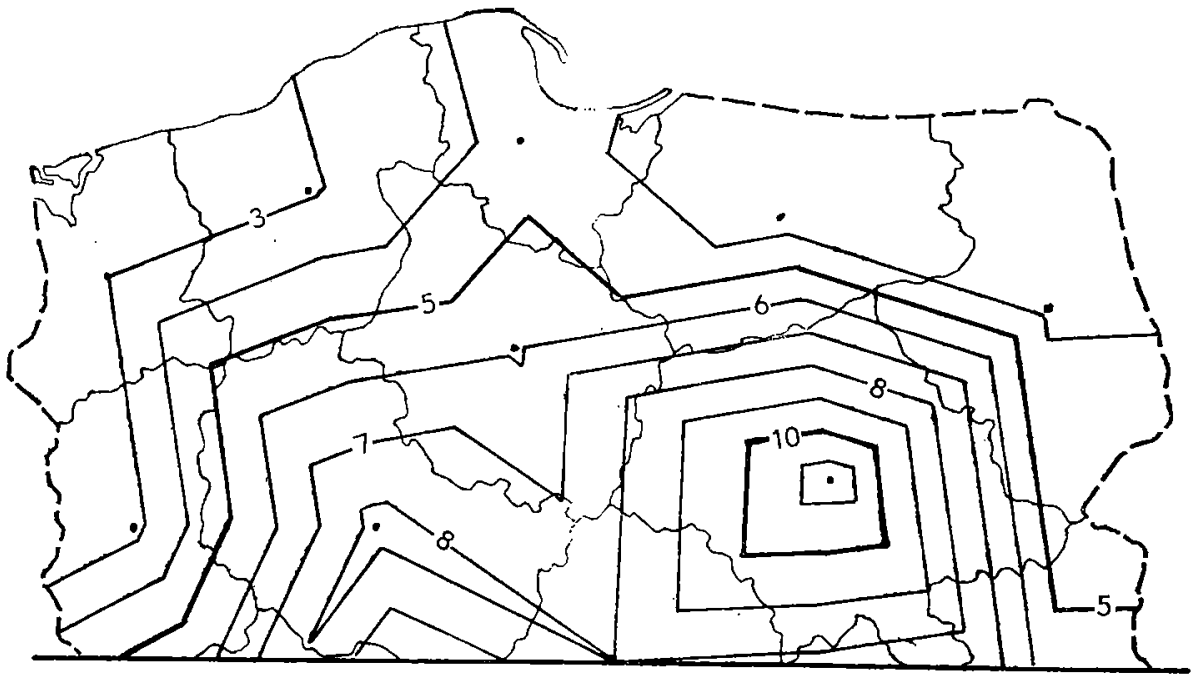

Fig. 6. Index of population development 
a)

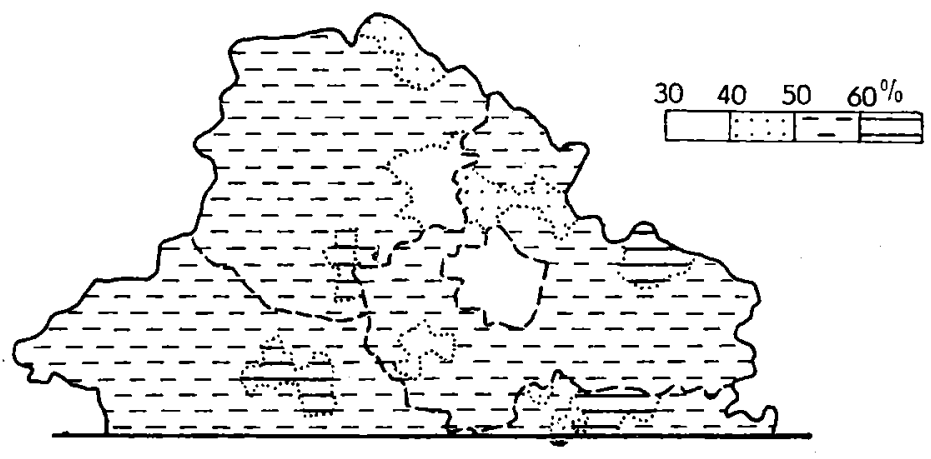

b)

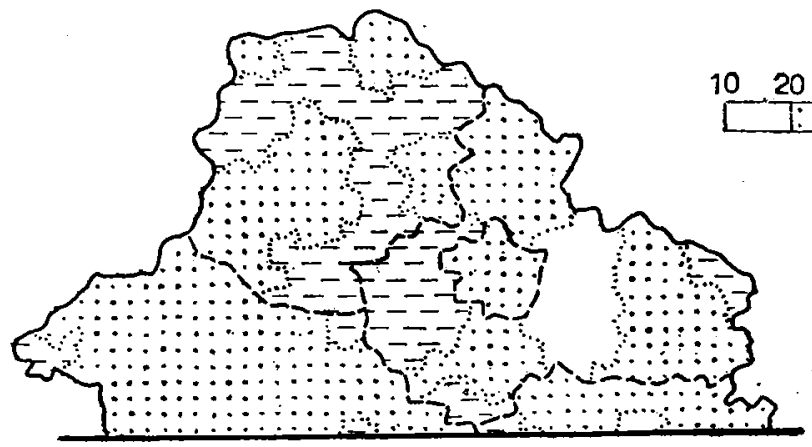

c)

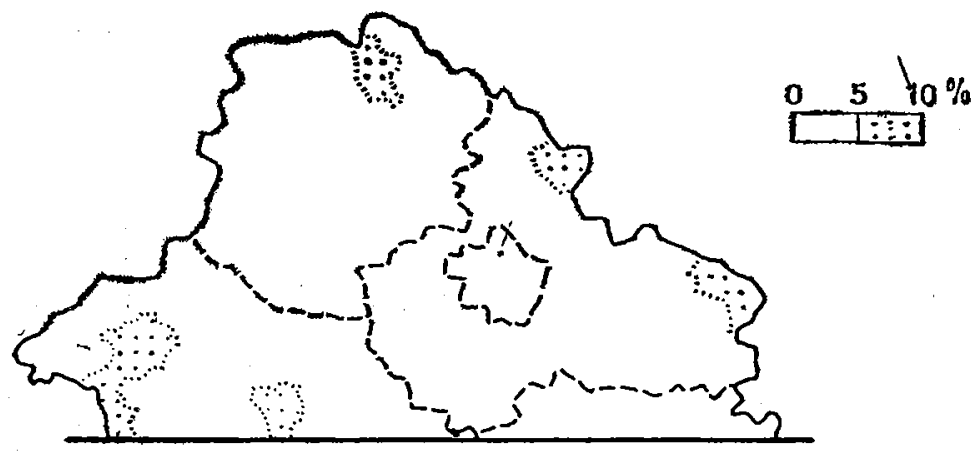

Fig. 7. a) Percentage of cereals (in total area sown)

b) Percentage of row crops (in total area sown)

c) Percentage of industrial crops (in total area sown) 


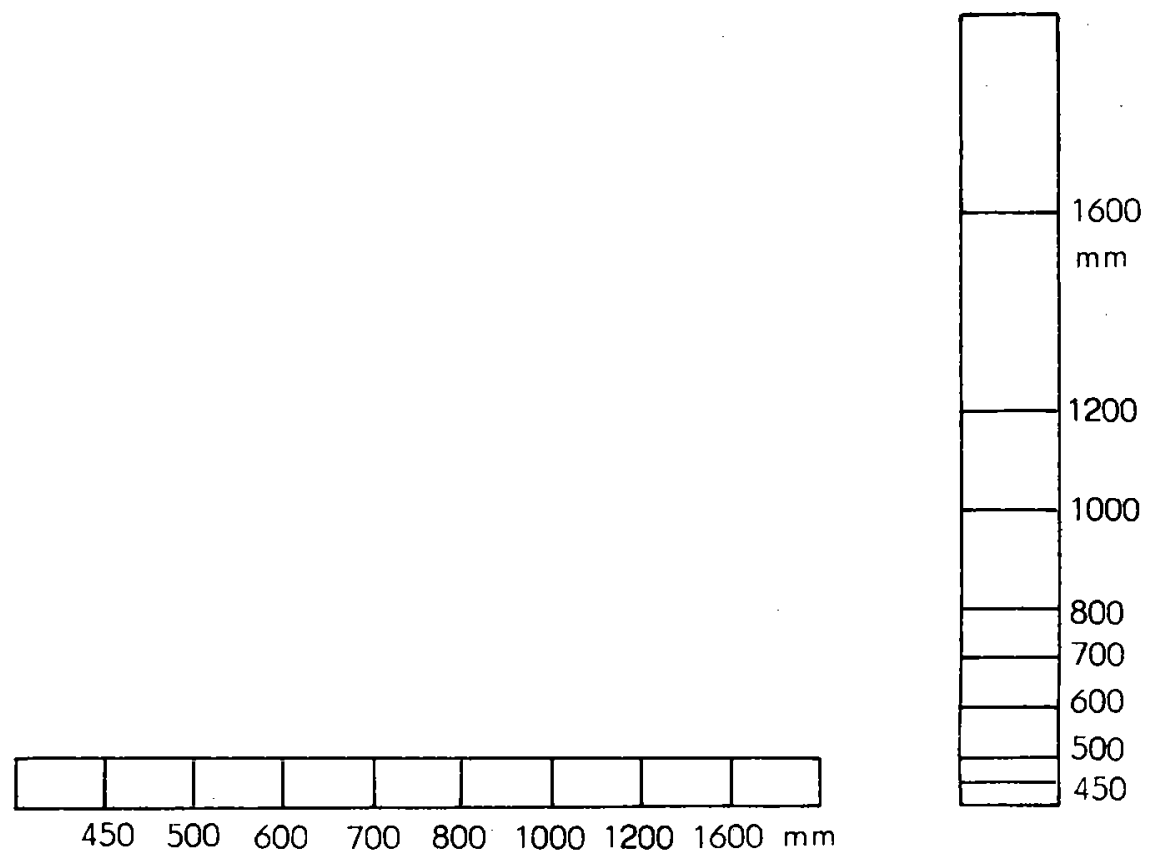

Fig. 8. Examples of legends for isoline maps, used in atlases and proposed by the author 
